\title{
ANALISIS KOMPONEN KIMIA EKSTRAK METANOL FRAKSI PETROLEUM ETER DAUN EUPATORIUM ODORATUM DENGAN GC-MS
}

\author{
Purwati $^{1}$, Sabirin Matsjeh ${ }^{2}$ \\ ${ }^{1}$ Program Studi Kimia, Jurusan MIPA Unsoed Purwokerto \\ ${ }^{2}$ Jurusan Kimia, FMIPA UGM Yogyakarta
}

\begin{abstract}
The purpose of this investigation was to analize the organic compounds of Eupatorium odoratum leaf and identification of the compounds using Gas Chromatography Mass Spectrometry (GC-MS). The sample was soaked in metanol. The extract of metanol was partitioned using petroleum ether. The extracts obtained were analyzed and identified by GC-MS. The results showed that in the extract of petroleum ether contained the organic compounds: germacrene, isocaryophyllene, 2,6,6,9-tetramethyl-1,4,8-cycloundecatriene, 1methyl-5-methylene-8-(1-methylethyl)-1,7-cyclodecadiene, 1,2,4a,5,8,8a-hexahydro-4,7dimethyl-1-(1-methylethyl) naphthalene, 1,12- dodecanediol, octahydro-1-(2-octyldecyl) pentalene, 3,7,11,15-tetramethyl-2-hexadecen-1-ol, methyl (12-acetyloxy)-9-octadecanoic, bis (2-ethylhexyl) phthalat, farnesol, 4,22-cholestadien-3-one and 1,2,3,5,6,7,8,8aoctahydro-1,4-dimethyl-7-(1-methylethenyl) azulene. In the extract of ethyl acetate contained the organic compounds: methyl heptadecanoic, hexadecanoic acid, methyl 13octadecenoic, 14,16-octadecadienal and octadecanoic acid.
\end{abstract}

Key word: Eupatorium odoratum, petroleum eter, GC-MS

\section{PENDAHULUAN}

Indonesia merupakan negara yang kaya akan sumber daya alam nabati. Sumber daya alam nabati ini sebagian besar sudah digunakan oleh orang sejak jaman dahulu sebagai obat tradisional dan kenyataannya dapat menyembuhkan berbagai penyakit. Kajian terhadap obat tradisional mempunyai arti penting, selain untuk mencari bahan obat baru juga untuk mengelola kekayaan alam Indonesia sendiri. Pada kenyataannya obat tradisional mulai banyak diminati karena pada umumnya tidak menimbulkan efek samping seperti halnya obat-obatan dari bahan kimia sintesis.

Tumbuhan wedusan (Eupatorium odoratum) merupakan salah satu tanaman obat tradisional di Indonesia yang mudah di dapat, tumbuh liar di mana-mana dan dapat digunakan sebagai obat luka baru, demam, malaria, batuk, dan menghentikan perdarahan.
Meskipun demikian tanaman ini masih sangat jarang dimanfaatkan oleh masyarakat bahkan sangat dibenci karena dianggap sebagai tanaman pengganggu yang sulit diberantas (Matsjeh, 1987).

Berdasarkan kenyataan tersebut maka pada penelitian ini akan dilakukan kajian pendahuluan dengan menganalisis komponen kimia ekstrak metanol fraksi petroleum eter daun Eupatorium odoratum dengan GC-MS (Gas Chromatography Mass Spectroscophy).

\section{METODE PENELITIAN Preparasi Sampel}

Daun Eupatorium odoratum yang baik dan bebas jamur dipisahkan dari batangnya, dicuci bersih, ditiriskan, dan dikeringkan dengan cara dianginanginkan ditempat yang teduh dan tidak terkena sinar matahari. Setelah kering, daun dihaluskan dengan blender. 


\section{Ekstraksi Daun Eupatorium odoratum}

Serbuk daun Eupatorium odoratum ditimbang seberat 100 gram dan direndam dalam 1 liter metanol $80 \%$ pada suhu kamar selama 24 jam sambil sesekali diaduk, kemudian disaring. Ekstrak metanol ditampung sedangkan residunya direndam kembali dalam 1 liter metanol 80\% selama 24 jam, disaring dan ditampung sehingga ekstrak metanol kurang lebih menjadi 2 liter. Ekstrak metanol ini diberi kode sebagai E1. E1 diuapkan pelarutnya dengan evaporator Buchi sampai tertinggal $1 / 5$ bagian dari volume awal $(400 \mathrm{~mL})$. E1 diekstrak lagi dengan $5 \times 150 \mathrm{~mL}$ petroleum eter menggunakan corong pisah hingga dihasilkan ekstrak petroleum eter (E2) dan ekstrak metanol (E3). E2 ditambahkan $\mathrm{Na}_{2} \mathrm{SO}_{4}$ anhidrat, disaring dan diuapkan pelarutnya. Selanjutnya dianalisis dengan GC-MS.

\section{HASIL DAN PEMBAHASAN Ekstraksi}

Hasil ekstraksi diperoleh ekstrak metanol fraksi petroleum eter daun Eupatorium odoratum berupa cairan kental, berwarna hijau tua dan beratnya
3,52 gram, sehingga rendemen yang dihasilkan sebesar 3,52\%.

Analisis Hasil Ekstraksi dengan GCMS

Hasil analisis dengan GC-MS dapat dilihat pada Gambar 1 . Berdasarkan Gambar 1, kromatogram menunjukkan bahwa ekstrak metanol fraksi petroleum eter daun Eupatorium odoratum paling tidak terdapat 14 senyawa. Waktu retensi dan kelimpahan relatif dari masing-masing puncak disajikan pada Tabel 1 .

\section{Identifikasi Senyawa dalam Ekstrak Metanol Fraksi Petroleum Eter Daun Eupatorium odoratum}

Fragmentasi puncak-puncak kromatogram ekstrak petroleum eter ditampilkan dalam Tabel 2. Berdasarkan spektra massa dari tiap puncak yang telah difragmentasi dengan mengacu pada literatur Barker,1999, Budzikiewicz, et. all.,1967, dan Silverstein, at. all.,1991, dan dibandingkan spektra standar dari literatur komputer, 13 puncak diantaranya diidentifikasi. Hasilnya ditunjukkan pada Tabel 2.

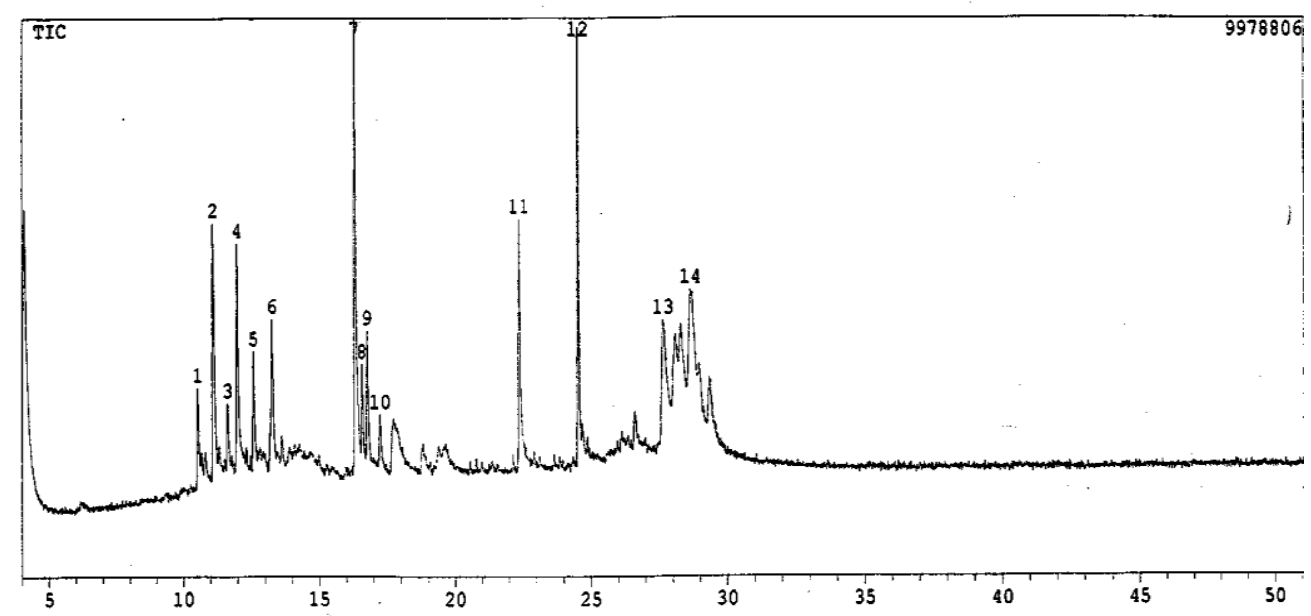

Gambar 1. Kromatogram ekstrak metanol fraksi petroleum eter daun Epatorium odoratum dengan $G C-M S$ 
Tabel 1. Waktu retensi dan kelimpahan relatif puncak-puncak kromatogram ekstrak metanol fraksi petroleum eter daun Eupatorium odoratum dengan GC-MS

\begin{tabular}{ccc}
\hline No. Puncak & Waktu retensi (menit) & Kelimpahan relatif (\%) \\
\hline 1 & 10,508 & 2,87 \\
2 & 11,075 & 10,62 \\
3 & 11,609 & 2,27 \\
4 & 11,956 & 7,86 \\
5 & 12,552 & 3,82 \\
6 & 13,224 & 6,99 \\
7 & 16,296 & 18,92 \\
8 & 16,559 & 3,49 \\
9 & 16,754 & 4,41 \\
10 & 17,229 & 1,80 \\
11 & 22,377 & 8,01 \\
12 & 24,530 & 11,21 \\
13 & 27,647 & 9,43 \\
\hline
\end{tabular}

Tabel 2. Fragmentasi dan identifikasi puncak kromatogram ekstrak metanol fraksi petroleum eter daun Eupatorium odoratum

\begin{tabular}{|c|c|c|c|c|}
\hline $\begin{array}{l}\text { No.Pun } \\
\text { cak }\end{array}$ & SI & $\mathbf{B M}$ & $\begin{array}{l}\text { Karakter Spektra Massa dan } \\
\text { Limpahan Relatif Ion, } \mathbf{m} / \mathbf{z}^{+}(\%)\end{array}$ & Senyawa \\
\hline 1 & 82 & 204 & $\begin{array}{llll}41(100), & 55(58,8), & 77(29,2), & 91(46,0), \\
105(82,4), & 119(83,0), & 133(13,1), & 147(5,7), \\
161(65,5), & 189(4,0), 204(8,00)\end{array}$ & $\begin{array}{l}\text { 1-metil-5-metilen- } \\
\text { 8-(1-metiletil)-1,6- } \\
\text { siklodekadiena }\end{array}$ \\
\hline 2 & 87 & 204 & 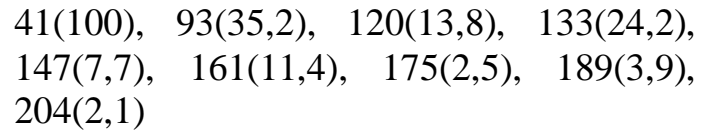 & Isokaryofilen \\
\hline 3 & 84 & 204 & $\begin{array}{lll}41(99,0), \quad 43(100), \quad 67(32,8), & 93(91,2), \\
107(16,3), & 121(20,3), \quad 135(5,8), & 163(2,2), \\
177(2,1), 189(1,9), 204(7,1) & \end{array}$ & $\begin{array}{l}\text { 2,6,6,9-tetrametil- } \\
1,4,8- \\
\text { sikloundekatriena }\end{array}$ \\
\hline 4 & 85 & 204 & $\begin{array}{lll}41(100), \quad 65(14,3), & 91(57,8), & 105(61,5), \\
119(36,5), 133(23,1), & 147(5,9), & 161(73,4), \\
175(1,1), 189(2,1), 204(10,2) & \end{array}$ & $\begin{array}{l}\text { 1-metil-5-metilen- } \\
\text { 8-(1-metiletil)-1,6- } \\
\text { siklodekadiena }\end{array}$ \\
\hline 5 & 83 & 204 & $\begin{array}{llll}41(100), & 55(56,4), & 77(28,3), & 91(51,3), \\
119(69,2), & 147(9,3), & 161(75,9), & 175(2,6), \\
189(11,8), 204(41,9) & & \end{array}$ & $\begin{array}{l}1,2,4 \mathrm{a}, 5,8,8 \mathrm{a}- \\
\text { heksahidro-4,7- } \\
\text { dimetil-1- (1-me- } \\
\text { tiletil) naftalena }\end{array}$ \\
\hline 7 & 87 & 202 & $\begin{array}{l}43(100), \quad 57(63), \quad 68(61,5), \quad 82(46,3), \\
109(12,3), 112(1,5), 123(20,9), 137(4,8)\end{array}$ & 1,12-dodekanadiol \\
\hline 8 & 84 & 362 & $\begin{array}{l}43(100), \quad 57(64,4), \quad 68(36,7), \quad 82(39), \\
95(33,6), 109(12,2), 110(5,9), 123(16,1), \\
124(8), 137(4,3), 151(2,7), 162(1), 180(1,4), \\
193(1,3), 207(2,6), 278(1,5)\end{array}$ & $\begin{array}{l}\text { Oktahidro-1-(2- } \\
\text { oktildesil)- } \\
\text { pentalena }\end{array}$ \\
\hline 9 & 87 & 296 & $\begin{array}{llrr}43(100), & 57(71,9), & 68(36,2), & 71(29,3), \\
83(29,3), & 95(35,6), & 97(18,3), & 109(13,1), \\
123(18,8), & 137(5,4), & 151(2,3), & 167(0,5), \\
197(0,7), 279(2) & & \end{array}$ & $\begin{array}{l}3,7,11,15- \\
\text { tetrametil-2- } \\
\text { heksadekena-1-ol }\end{array}$ \\
\hline
\end{tabular}




\begin{tabular}{|c|c|c|c|c|c|c|}
\hline 10 & 84 & 354 & $\begin{array}{ll}43(100), & 74(57,9), \\
115(1,9), & 129(2,7), \\
171(2,6), & 185(3,8), \\
270(1,5) & \end{array}$ & $\begin{array}{r}87,(29,4) \\
143(8,1) \\
199(1,0)\end{array}$ & $\begin{array}{l}101(2,5), \\
157(1,1), \\
227(4,7),\end{array}$ & $\begin{array}{l}\text { Metil } \\
\text { asetiloksi)-9- } \\
\text { oktadekanoat }\end{array}$ \\
\hline 11 & 87 & 390 & $\begin{array}{ll}43(71,4), & 57(70,4), \\
104(6,1), & 132(2,5), \\
279(5,6) & \end{array}$ & $\begin{array}{l}71(37,1), \\
149(100), 1\end{array}$ & $\begin{array}{l}83(15,1), \\
167(35,9),\end{array}$ & $\begin{array}{l}\text { Bis(2-etilheksil) } \\
\text { ftalat }\end{array}$ \\
\hline 12 & 90 & 222 & $\begin{array}{l}42(58), 55(14,3), 69(1 \\
95(15), \quad 121(7,1), \\
191(1,8), 203(1,2), 21\end{array}$ & $\begin{array}{l}00), 81(58,4) \\
136(7,1), \\
7(0,7)\end{array}$ & $\begin{array}{r}, 93(8,5) \\
175(1,5)\end{array}$ & $\begin{array}{l}\text { 3,7,11-trimetil } \\
\text { 2,6,10-dodekatrien- } \\
\text { 1-ol }\end{array}$ \\
\hline 13 & 73 & 382 & $\begin{array}{l}43(95,4), \quad 55(100), \\
111(8,0), \quad 123(11,5), \\
175(3,6), \quad 229(1,6), \\
269(1,9), 299(3,2)\end{array}$ & $\begin{array}{l}69(50,9), \\
147(10,2), \\
245(2,1),\end{array}$ & $\begin{array}{r}83(40,2), \\
161(7), \\
253(3,6),\end{array}$ & $\begin{array}{l}\text { 4,22-kolestadien-3- } \\
\text { on }\end{array}$ \\
\hline 14 & 74 & 204 & $\begin{array}{l}41(100), \quad 55(95,4), \\
93(63,1), 107(63,5), \\
147(33,3), 161(28,3),\end{array}$ & $\begin{array}{l}\text { 67(63,2), } \\
121(62,9), 1 \\
189(50,3), 20\end{array}$ & $\begin{array}{l}79(33,3), \\
135(70,1), \\
04(40,3)\end{array}$ & $\begin{array}{l}\text { 1,2,3,5,6,7,8,8a- } \\
\text { oktahidro-1,4- } \\
\text { dimetil-7-(1-me- } \\
\text { tiletenil)-azulena }\end{array}$ \\
\hline
\end{tabular}

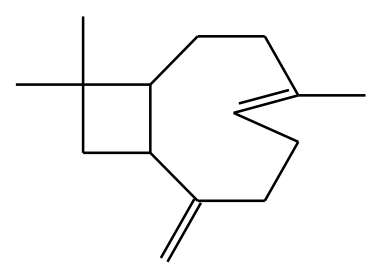

isokaryofilen<smiles>C=C1CC/C=C(\C)CC/C(C(C)C)=C\CC1</smiles>

1-metil-5-metilen-8-( 1-metiletil) 1,7-siklodekadiena

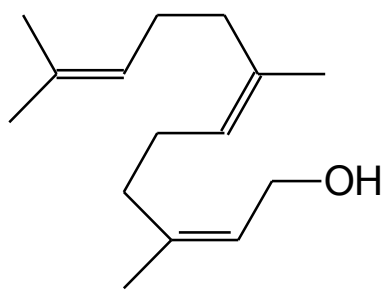

Farnesol

Bis ( 2-etilheksil) Ftalat

Gambar 2. Komponen Utama dari Hasil Isolasi

\section{KESIMPULAN}

Berdasarkan hasil penelitian dan pengamatan yang telah dilakukan dapat disimpulkan bahwa:

1. Hasil analisis dengan GC-MS komponen kimia ekstrak metanol fraksi petroleum eter daun Eupatorium odoratum mengandung senyawa: germacrena, isokaryofilen, 2,6,6,9-tetrametil-1,4,8-

sikloundekatriena, 1-metil-5-metilen8-(1-metiletil)-1,7-siklodekadiena, 
1,2,4a,5,8,8a-heksahidro-4,7-dimetil1-(1-metiletil) naftalena, 1,12dodekanadiol, oktahidro-1-(2oktildesil) pentalena, 3,7,11,15tetrametil-2-heksadeken-1-ol, metil (12-asetiloksil)-9-oktadekanoat, bis (2-etilheksil) ftalat, farnesol, 4,22kolestadien-3-on dan 1,2,3,5,6,7,8,8a-

\section{DAFTAR PUSTAKA}

Barker, J., 1999. Mass Spectrometry. second edition. John Wiley and Sons. Chicester.

Budzikiewicz, H., Djerassi, C., dan William, D.H. 1967 Mass Spectrometry of Organic Compound. Holden-Day Inc. San Fransisco.

Kitson, F.G., Larsen, B.S., dan Mc Ewen, C.N. $1996 . \quad$ "Gass Chromatography and Mass Spectrometry a Practical Guide". Academic Press. San Diego. oktahidro-1,4-dimetil-7-(1-

metiletenil) azulena.

2. Komponen kimia utama dari ke-13 senyawa di atas adalah: isokaryofilen, 1-metil-5-metilen-8-(1-metiletil)-1,7siklodekadiena, 1,12- dodekanadiol, bis (2-etilheksil) ftalat, dan farnesol.

Matsjeh, S., 1987, "Hasil-hasil Semulajadi dari Beberapa Obat Tradisional Melayu”. Disertasi. Universitas Sains Malaysia. Malaysia.

Sastrohamidjojo, H. 1988. "Interpretasi Spektra Massa". GMU Press. Yogyakarta (Terjemahan dari McLafferty. 1980. " Interpretation of Mass Spectra". third edition. University Science Book).

Silverstein, R.M., Bassler, G.C, and Morril, T.C. 1991. "Spectrometric Identification of Organic Compounds". fifth edition. John Wiley and Sons Inc. New York. 